\title{
A Study on the Influencing Factors of IPO Pricing and Policy Research in Chinese Stock Market
}

\author{
Chen Litong \\ School of Management, HeFei University of Technology, China \\ litong@163.com
}

Keywords: IPO, Pricing factors, Policy

\begin{abstract}
The stock market is of financing function. So the IPO is an important financing channels and the rational use of this function determines the healthy development of China's capital market directly. The rationality of IPO primarily reflects on the IPO pricing .By reviewing previous IPO pricing theory, we establish the IPO pricing multifactor model and lead in macroeconomic early warning index to model for the first time. The empirical results validate the rationality of the model, and the relevant statistics statistical test effect is good. The empirical results have positive reference meaning to IPO pricing of our country stock market.
\end{abstract}

\section{Introduction}

IPO (Initial Public Offerings) refers that the company issued the common stock to the Public for the first time .The IPO will takes more money into the listed company to promote its development and expansion. In the process of the allocation of resources, offering price plays a crucial role: on the basis of the efficient market theory, if the capital market is effective, the price should be equal to the company's intrinsic value, thus it will allocate the scarce financial resources to the optimal producers effectively, and achieve the result of optimal allocation of resources. On the other hand, the IPO price will deviate from the company's intrinsic value, and lead to the emergence of inefficient pricing [1].Study found that in the past two or three decades, including the United States, there are 14 of 15 countries that the number of IPO companies is proportional to the stock market scale each year. And in 14 the countries, there are 10 countries IPO quantity are negative to next year's market return [2].However our country securities market IPO project for the "three highs" problems, and has been plagued by stock market participants. From excessive enthusiasm of new shares and regulators repeated deliberation, those emergences reflects our country securities market failed to allocate resources rationally and related policy system is imperfect. So exploring the factors of IPO pricing has important research value for rational allocation of social resources of our country securities market and the enterprise financing. Share issuance system is one of the most basic part of the construction. We can incentive and constraint market participants, clear the responsibilities of relationship between market subjects, strengthen the competition mechanism by stock issuing system. And it also has important effect to the efficient allocation of capital and protecting the interests of the investors. On November 30, 2013, the SFC issued "about further improve the degree of market pricing of new shares" to push the marketization of distribution system reform. It is our country economic system reform path.

\section{Research review}

Successful IPO is very important for the company's long-term development, because it is helpful for enterprises to raise the funds smoothly for expanding production or business operation. It also can improve the enterprise capital structure and governance structure. The majority of international IPO pricing research mainly include IPO pricing factor regression model method, discount cash flow method (including William dividend discount models, free cash flow model of AlfredRappaport, Preinreich residual income model, etc.), economic income value added (EVA) and comparable company method. IPO pricing reflects the investor's expectations of the company. So the industry average p/e ratio and earnings per share will affect the IPO pricing. Fen Tao, 
yong-ming Wang (2009) [3] established the IPO pricing model with the industry p/e ratio, earnings per share and net profit growth rate in the article: the IPO pricing model and the empirical research in China stock market. Jin-chao Zhu (2011) [4] focus on influence factors about issued capital, total equity, total assets, net assets, inventory turnover, accounts receivable turnover rate, the growth rate of operating income, net profit growth rate of IPO pricing in the gem IPO pricing research. ZhuXiPing, ze-long Wang (2010) [5] analyze the relationship between the relevant financial indicators and the IPO pricing of the small and medium-sized board listed company in the empirical analysis of IPO pricing factors. Scholars also proposed some other factors, which affect the price of IPO issuance, including corporate governance, underwriter reputation, industry, market sentiment, distribution system, investor sentiment and so on. Such as Xiao-liang Wang (2007) [6] had empirical study on factors affecting IPO efficiency and introduced a new explanatory variables market atmosphere. Even if the IPO can be priced reasonable, it still may appear IPO underpricing phenomenon. So many scholars research on IPO pricing efficiency. Xun-bo Chen, Yan-lin He (2013) [7] research China's IPO pricing efficiency based on the rate of IPO underpricing and the EFF values of the comparative analysis and point out the basic way which is the return to the origin of market-oriented reform and the government out of the control of price intervention to improve the efficiency of IPO. The IPO is game between companies, underwriters and investors. The original shareholders as an important decision makers and supervisors take a very important influence in the issue of pricing efficiency [8].And Xiaobin Ren (2014) [9] think under the imperfect China's capital market, even though IPO is priced reasonably, there are still many investors chasing after because the market lacks of adequate investment products. Studies have found that the more difference between institutions offer, the more serious difference exist in institutions in the process of quotation. Further research shows that a high level of market pricing problem due to the difference of institutions price. And it lead s to the emergence problem of "three highs" [10].

\section{Establishment of Model and Test}

Research strategy. (1) Research frame. Persistence of "three high" problem in our country will inevitably cause people to question the rationality of IPO in China. High price earnings ratio, high price, large amount of funds is mainly caused by unreasonable pricing mechanism. There are many methods of IPO pricing, including factor regression analysis method, the economic profit analysis method, discounted cash flow method. This article will research some related factors effect by using the factor regression analysis method from the macro economic operation, the stock market operation, and company fundamentals three research directions. We choose some indexes for every directions. The macroeconomic situation: The early warning index, the operation of the stock market situation : choose Hushen300 stock index and company fundamentals by size, earnings per share, net asset per share three factors. Establish an IPO pricing multiple linear regression model which relates to early warning index, the CSI 300 index, issue size, earnings per share, net asset per share, analyze the influence of various factors on IPO pricing and related policies. (2) Sample selection and data source

(1) Sample selection

This article chose 223 listed companies as the study sample range from 2011.1 to 2014.12. Descriptive statistics as picture 1:

Table 1 Sample Descriptive Statistics

\begin{tabular}{ccccccccccc}
\hline Mean & $\begin{array}{c}\text { Media } \\
\mathrm{n}\end{array}$ & Max & Min & $\begin{array}{c}\text { Std.De } \\
\text { v. }\end{array}$ & $\begin{array}{c}\text { Skewne } \\
\text { ss }\end{array}$ & $\begin{array}{c}\text { Kurtos } \\
\text { is }\end{array}$ & $\begin{array}{c}\text { Jarque-Be } \\
\text { ra }\end{array}$ & $\begin{array}{c}\text { Probabili } \\
\text { ty }\end{array}$ & Sum & $\begin{array}{c}\text { Observatio } \\
\text { ns }\end{array}$ \\
\hline 19.74 & 18.66 & 67.00 & 2.17 & 1.139 & 1.543 & 6.623 & 210.466 & 0.000 & 4402.7 & 223 \\
3 & 0 & 0 & 0 & & & & & & 40 & \\
\hline
\end{tabular}




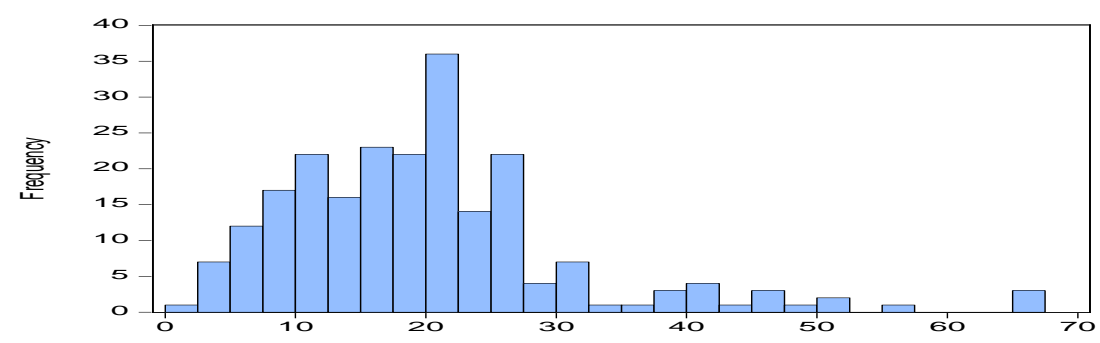

Picture 1 Sample First price Descriptive Statistics

We can know that sample stock first price's mean is 19.74, min and max are 2.17 and 67.00. skewness is $1.50>0$. Rightly skew distribution.

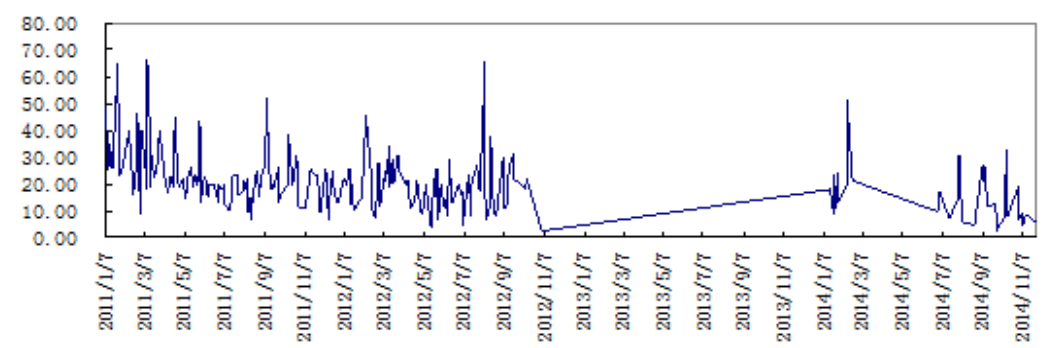

Picture 2 Tendency of first price

(2) Data source

The data : IPO first price, Early warning index, Scale, EPS, BPS are all from The giant spirit database. CSI 300 stock index comes from Sina Finance.

Method design. This paper adopts the multiple linear regression analysis, and we establish a correlation regression model including five factors: IPO pricing, Early warning index (YJ), CSI 300 index (SS), Issuing scale (IS), Earnings per share (EPS) and Net assets per share (BPS) .Then puts forward the related hypothesis:

(1) IPO pricing is positively related with early warning index $\left(\beta_{1}>0\right)$; early warning index includes all aspects of economic activity as production, employment, income distribution and demand. It can comprehensively reflect the changes of the overall economy. When the national macro economic trend change, macroeconomic index will also change accordingly. At the same time, the IPO pricing will be higher with the better trend of macroeconomic, and vice versa.

(2) IPO pricing is positively related with the CSI 300 index $\left(\beta_{2}>0\right)$; the CSI 300 index is the barometer of Shanghai and Shenzhen two market. The sample was selected from the Shanghai and Shenzhen two index securities market, covering most of the circulation market value. It can reflect the mainstream market investment returns.

(3) IPO pricing and issuing scale show a negative correlation $\left(\beta_{3}<0\right)$; When the issued share capital is certain, a larger issue size should be with a low pricing , and vice versa.

(4) IPO pricing is positively related with earnings per share $\left(\beta_{4}>0\right)$; Earnings per share means that common shareholders can enjoy enterprise net profit or take the enterprise net loss by holding a shares, So it is often used to reflect the operating results of the enterprise and measure common stock profit level or the investment risk. It will be clear that the higher profit of the investment earnings per share, the smaller investment risk will be.

(5) IPO pricing is positively related with net assets per share $\left(\beta_{5}>0\right)$; Net assets per share reflects the present value of assets per share. So when net assets per share is higher, the company's operations will be better with a high IPO pricing.

For $P_{\mathrm{i}}$ is the IPO price, according to the above hypothesis we establish a multiple linear regression model;

$$
P_{i}=\alpha_{0}+\beta_{1} Y J+\beta_{2} S S+\beta_{3} I S+\beta_{4} E P S+\beta_{5} B P S+\varepsilon
$$

Among them: $\alpha_{0}$ for the constant term, $\varepsilon$ for IPO pricing errors items. 


\section{The empirical result analysis}

\section{Independent variable linear test.}

\begin{tabular}{|c|c|c|c|}
\hline \multicolumn{4}{|c|}{ Table 2 Independent variable linear test form } \\
\hline variable name & Variable symbol & Tolerance & VIF \\
\hline Early warning index & YJ & 0.468 & 2.136 \\
\hline The CSI 300 stock index & SS & 0.458 & 2.182 \\
\hline Issuing scale & IS & 0.975 & 1.026 \\
\hline Earnings per share & EPS & 0.690 & 1.45. \\
\hline Net assets per share & BPS & 0.698 & 1.434 \\
\hline
\end{tabular}

This model involves five independent variables. if there is obvious multicollinearity between the independent variables, it will be serious influence on the fit of the whole model. So before model analysis we should check the presence of multicollinearity among the independent variables. Analysis each variable tolerance and variance inflation factor by SPSS software and the result is shown in the table above. Each variable linear tolerance is greater than 0.1 , so we can roughly judge that collinearity is not very serious among variables, then we can do further empirical analysis.

Model coefficient and significance test.

(1) Model coefficient test

Table 3 Regression coefficient test table

\begin{tabular}{cccccc}
\hline Model & $\begin{array}{c}\text { Coefficients } \\
\text { B }\end{array}$ & $\begin{array}{c}\text { Standard } \\
\text { error }\end{array}$ & $\begin{array}{c}\text { standard } \\
\text { coefficient }\end{array}$ & $\mathrm{t}$ & sig \\
\hline$\alpha_{\mathrm{o}}$ & -26.357 & 6.181 & & -4.264 & 0.000 \\
\hline $\mathrm{YJ}$ & 0.162 & 0.079 & 0.165 & 2.058 & 0.041 \\
\hline $\mathrm{SS}$ & 0.008 & 0.003 & 0.250 & 3.088 & 0.002 \\
\hline $\mathrm{IS}$ & 0.000 & 0.000 & -0.221 & -3.987 & 0.000 \\
\hline EPS & 9.318 & 1.747 & 0.352 & 5.335 & 0.000 \\
\hline BPS & 0.876 & 0.445 & 0.129 & 1.968 & 0.050 \\
\hline
\end{tabular}

From form 3:

$\alpha_{0}=-26.357 \quad \beta_{1}=0.165>0 \quad \beta_{2}=0.250>0 \quad \beta_{3}=-0.221<0 \quad \beta_{4}=0.352>0 \quad \beta_{5}=0.129>0$ match the previous assumptions. So the Multiple linear regression equation is :

$P_{\mathrm{i}}=-26.357+0.165 Y J+0.250 S S-0.221 I S+0.352 E P S+0.129 B P S$

Egression coefficient significance analysis:

$\mathrm{P}(\mathrm{a})=0.000<0.05 ; \quad \mathrm{P}(\mathrm{YJ})=0.041<0.005 ; \quad \mathrm{P}(\mathrm{SS})=0.002<0.05 ; \quad \mathrm{P}(\mathrm{IS})=0.000<0.05 ; \quad \mathrm{P}(\mathrm{EPS})$ $=0.000<0.05 ; \mathrm{P}$ (BPS) $=0.050 \leqslant 0.05$;

$P$ values are less than 0.05 , which indicated that various factors influence on IPO pricing is more significant.

(2)The model test of significance

Table 4 model test of significance

\begin{tabular}{cccccc}
\hline & Quadratic sum & df & mean square & F & Sig. \\
\hline regression & 9658.100 & 5 & 1931.620 & 23.361 & 0.000 \\
\hline residual & 17859.893 & 216 & 82.685 & & \\
\hline total & 27517.993 & 221 & & & \\
\hline
\end{tabular}


$\mathrm{F}=23.361>\mathrm{F}(5,216)=2.21 ; \mathrm{P}=0.000<0.05 ;$ So Model is highly significant.

\section{Conclusion and policy research}

(1) Through the regression analysis of the early warning index, the CSI 300 index, issuance, earnings per share and net assets per share five internal and external factors, this paper comprehensive interpret IPO pricing. And we establish the multivariate regression model of IPO pricing of listed companies. The test results show that the model is statistically significant, and the statistical test effect is better.

(2) In this paper, We analysis that the 20 new companies, listed in 2014and 2015, average starting price is 13.61 Yuan, through the model calculating the average starting price is 9.46 Yuan. The results show that the model can effectively reduce IPO under pricing rate. The rational investment and guide the rational allocation of limited capital has positive significance.

\section{References}

[1] W. Wang, H.Y. Song. Study on Boundaries and Model of Multi-bodies Supply of Agricultural Information Service, J. Journal of Hubei University of Economics. 3(2013) 66 - 70.

[2] Xiaoya Zhen Liu Fei. Small and medium-sized board listed company IPO pricing efficiency measure under the condition of information asymmetry in our country [J]. Journal of investment research, 2014 (6) : 107-117.

[3] Tim Loughran, Jay Ritter. The new issues puzzle [J]. Journal of Finance, 1995:24-26.

[4] Feng Tao, yongming Wang. China's securities market IPO pricing model and its empirical study [J]. Journal of statistics and information BBS, 2009 (1) : 58-60.

[5] Jinchao Zhu. The research of the gem IPO pricing affecting factors [D]. Tianjin: nankai university, 2011.

[6] XiPing Zhu Zelong Wang. Small and medium-sized boards of listed companies empirical analysis of the factors affecting IPO pricing [J]. Modern property (middle), 2010 (6) : 30 and 31. 